\title{
IS THERE CHANGE ON THE B-THEORY OF TIME?
}

\author{
Luca Banfi ${ }^{1}$ \\ ${ }^{1}$ University College Dublin \\ Review article - Received: 02/06/2020 Accepted: 01/07/2021
}

\begin{abstract}
The purpose of this paper is to explore the connection between change and the B-theory of time, sometimes also called the Scientific view of time, according to which reality is a fourdimensional spacetime manifold, where past, present and future things equally exist, and the present time and non-present times are metaphysically the same. I argue in favour of a novel response to the much-vexed question of whether there is change on the B-theory or not. In fact, B-theorists are often said to hold a 'static' view of time. But this far from being innocent label: if the B-theory of time presents a model of temporal reality that is static, then there is no change on the B-theory. From this, one can reasonably think as follows: of course, there is change, so the B-theory must be false. What I plan to do in this paper is to argue that in some sense there is change on the B-theory, but in some other sense, there is no change on the B-theory. To do so, I present three instances of change: Existential Change, namely the view that things change with respect to their existence over time; Qualitative Change, the view that things change with respect to how they are over time; Propositional Change, namely the view that things (i.e. propositions) change with respect to truth value over time. I argue that while there is a reading of these three instances of change that is true on the B-theory, and so there is change on the B-theory in this sense, there is a B-theoretical reading of each of them that is not true on the $B$-theory, and therefore there is no change on the B-theory in this other sense.
\end{abstract}

Keywords: Change; B-theory of time; existence; properties; propositions 


\section{Introduction}

The purpose of this paper is to explore the connection between change and the B-theory of time, sometimes also called the Scientific view of time, according to which reality is a four-dimensional spacetime manifold, where past, present and future things equally exist, and the present time and non-present times are metaphysically the same. I argue in favour of a novel response to the much-vexed question of whether there is change on the B-theory or not. ${ }^{1}$

In fact, B-theorists are often said to hold a 'static' view of time. But this far from being an innocent label: if the B-theory of time presents a model of temporal reality that is static, then there is no change on the B-theory. From this, one can reasonably think as follow: of course there is change, so the B-theory must be false. What I plan to do in this paper is to argue that in some sense there is change on the B-theory, but in some other sense, there is no change on the B-theory. To do so, I present three instances of change: Existential Change, namely the view that things change with respect to their existence over time; Qualitative Change, the view that things change with respect to how they are over time; Propositional Change, namely the view that things (i.e. propositions) change with respect to truth value over time. I argue that while there is a reading of these three instances of change that is true on the B-theory, and so there is change on the B-theory in this sense, there is a reading of each of them that is not true on the B-theory, and therefore there is no change on the B-theory in this other sense.

\section{Three Instances of Change}

Bubbles, chemical reactions, flowers, butterflies, human beings (and so on) exist, but do not exist forever. More generally, many things change with respect to existence. Hence, the following counts as an instance of change:

EXISTENTIAL CHANGE: things change with respect to existence over time. ${ }^{2}$

\footnotetext{
${ }^{1}$ For a classic discussion see McTaggart (1927), Prior (1968) and Williams (1951); for a contemporary discussion see Sider (2011, Ch. 11) and Williamson (2013, ch. 8).

${ }^{2}$ Existential Change may take different forms. Some believe it to be true, since they believe that things both begin and cease to exist, such as Lowe (2003, 2006, 2009), Prior (1968), and Zimmerman (2008); others, think of it to be true because things begin to exist, but then do not cease to do so (Correia and Rosenkranz 2018).
} 
It is important to be clear about the meaning of 'exist' in Existential Change: 'exist' means here the same as 'being' or 'being something' or 'being identical to something' in the most unrestricted sense. What I am assuming here is the standard meaning of existence assumed by most contemporary metaphysicians. ${ }^{3}$ So, for a cat to exist is for it to be something, for a car to exist is for it to be something, and so on. Nothing more or less.

For the sake of convenience, it is useful to introduce a more formal way of expressing Existential Change, and the following instances of change. To do so, let's appeal to the language of free tense logic, ${ }^{4}$ the language that implements the language of free logic with the so-called tense operators such as the past tense operator 'It was the case that' or 'It is the case at some past time that' (symbolised as 'P') and the future tense operator 'It will be the case that' or 'It is the case at some future time that' (symbolised as ' $F$ '). From these, one can further define the operator 'It is sometimes the case that' or 'It is the case at some time' (symbolised as ' $\mathrm{S}$ ', where ' $\mathrm{S} \varphi$ ' is defined as ' ${ }^{5} \mathrm{P} \varphi \vee \varphi \vee \mathrm{F} \varphi$ '), and the operator 'It is always the case that' or 'It is the case at all times' (symbolised as 'A', where ' $\mathrm{A} \varphi$ ' is defined as ' $\mathrm{P} \varphi \wedge \varphi \wedge \mathrm{F} \varphi$ ').

\footnotetext{
${ }^{3}$ See van Inwagen (2009) for a detailed discussion of the view.

${ }^{4}$ I say free tense logic instead of quantificational tense logic, since the latter arguably entails the falsity of Existential Change (see, for instance, Bacon (2013) and Williamson (2013)). I will not rehearse all the details of the argument here, but a brief discussion may help. Given quantificational tense logic, every instance of ' $\exists$ x $a=x$ ' is proved to be true (where ' $a$ ' stands for any singular term in that language, ' $\exists x a=x$ ' says that there is something identical to $a$ ). Given the temporal analogue of the rule of necessitation, one can infer from the true $\varphi$ that it is always the case that $\varphi$, such that one can infer ' $\mathrm{A}(\exists x a=x)$ ' (which says that it is always the case that there is something identical to $a$ ) from ' $\exists x a=x$ '. Now, by the rule of generalization, that allows one to infer from the true $\varphi$ the true $\forall x \varphi$, one can infer ' $\forall y \mathrm{~A}(\exists x y=x)$ ' (which says that everything always exists) from ' $\mathrm{A}(\exists x a=$ $x$ )'. So, given quantificational tense logic, one can prove that everything always exists, thus contradicting Existential Change.

If one adopts a free tense logic, one can deny that every instance of ' $\exists x a=x$ ' is proved to be true in the first place. In fact, given a free tense logic, one can reject the axiom of universal instantiation of quantificational tense logic, namely ' $\forall x \varphi x \rightarrow \varphi \mathrm{a}$ ', from which ' $\exists x a=x$ ' is inferred, and accept the weaker axiom of free universal instantiation, such as ' $\forall y(\forall x \varphi x \rightarrow \varphi y)$ ' (which says that for every way everything in the domain is, there is something we can name in the domain that is in that way). Therefore, those who accept a free tense logic have the logical resources to accept that some instances of ' $\exists x a=x$ ' are false, when ' $a$ ' fails to denote a member of the domain of quantification, and also to resist the above argument for the inconsistency between quantificational tense logic and Existential Change.

${ }^{5}$ In fact, there the list of tense operators I present is not exhaustive, as there are further tense operators such as 'It has always been the case that' (symbolised as ' $\mathrm{H}$ ') and 'It is always going to be the case that' (symbolised as ' $G$ '). One can also make use of the so-called metric tense operators, operators of the form 'It was the case $n$ units of time ago'.
} 
So, one can regiment Existential Change as:

EXISTENTIAL CHANGE: Sometimes, something is not always something. (Formally: ' $\mathrm{S}(\exists x \neg \mathrm{A}(\exists y y=x))$ ')

There is not just change in what exists over time, however. Tim was a kid, and he is an adult, Lisa is seated, even though she was standing, and Barack Obama was the US President, but he is not anymore. Therefore, a further instance of change is the following:

QUALITATIVE CHANGE: things change with respect to how they are over time. ${ }^{6}$

If we understand the predicates 'is adult', 'is seated' and 'is the US President' as expressing properties or qualities, Qualitative Change amounts to the view that things change with respect to properties or qualities over time: Tim does not always bear the property of being an adult, Lisa does not always bear the property of being seated, and Barack Obama does not always bear the property of being the US President.

Qualitative Change is naturally linked with the view that things persist through time. Take Lisa: it is not just that Lisa, for example, changes as she is seated, but she was standing, but also that Lisa exists and she is seated, and existed and she was standing; analogously, Lisa will exist and will be standing too.

More specifically, for Lisa to change with respect to her properties, she must remain in existence through time. That's the dynamic phenomenon philosophers call persistence:

PERSISTENCE: things persist through time.

For Lisa to change with respect to her properties is not for Lisa to begin to exist when she gains the property of being seated, and for her to cease to exist when she loses the property of being seated and gains the property of being standing. As a matter of fact, Lisa exists both when she is seated and when she was and will be standing. It is one and the same thing that both changes and persists through time: it is one and the same Lisa that is seated and exists, and did exist and was standing.

\footnotetext{
${ }^{6}$ Those who believe in Qualitative Change include, for example, Hinchliff (1996) and Prior (1968, 78-9).
} 
So, Qualitative Change and Persistence count as a single instance of change (or so I claim): call this instance of change Qualitative Change plus Persistence. One can express Qualitative Change plus Persistence more formally as follows, where F stands for some property:

\section{QUALITATIVE CHANGE PLUS PERSISTENCE:}

Sometimes, some $x$ bears some $\mathrm{F}$ but $x$ does not always bear F. (Formally: ' $\mathrm{S}(\exists x \exists \mathrm{F}(\mathrm{F} x \wedge \neg \mathrm{AFx}))$ ')

The last instance of change that I wish to consider is change in what is the case, or what is true, over time. One can derive such instance of change from either Existential Change or Qualitative Change. Consider Lisa: since Lisa exists, it the case that Lisa exists. Moreover, since Lisa is seated, it is the case that Lisa is seated. But Lisa does not always exist and is not always seated. Therefore, it is not always the case that Lisa exists or that Lisa is seated. By taking talks about "being the case" as equivalent to "being true", where the primary bearers of truth and falsehood are propositions, then one can say that the propositions that Lisa exists and that Lisa is seated are true, but not always so. As a matter of fact, they change with respect to truth value. Here is the third instance of change:

PROPOSITIONAL CHANGE: things (i.e., propositions) change with respect to truth value over time. ${ }^{7}$

Very much as with Existential Change and Qualitative Change plus Persistence, one can express Propositional Change in more formal terms as follows, where ' $p$ ' stands for a propositional variable:

PROPOSITIONAL CHANGE: Sometimes, there is some true proposition that is not always true. (Formally: ' $\mathrm{S}(\exists \mathrm{p}$ $(\mathrm{p} \wedge \neg \mathrm{A}(\mathrm{p}))^{\prime}$

This concludes the presentation of three entirely plausible instances of change.

In this paper, my purpose is to argue that the B-theory of time, which I will introduce in more detail in the following section (Section 2), is consistent with certain readings of such instances of change; thus, in this sense, there is change on the B-theory. Nevertheless, I argue that there is a reading of each of them that is false on the B-theory, and therefore that in this other sense, there is no change on the B-theory. The plan for the remaining part

${ }^{7}$ The view is extensively defended in Borgaard (2012) and Cappelen and Hawthorne (2009) among others. 
of the paper is as follows. In Section 2, I say more about how to understand the B-theory; in Section 3 I discuss the connection between Existential Change and the B-theory; in Section 4, I discuss the connection between Qualitative Change plus Persistence and the B-theory; in Section 5, I discuss the connection between Propositional Change and the B-theory.

\section{The B-theory of time}

$B$-theorists, those who defend the B-theory of time, ${ }^{8}$ typically hold that reality consists of a four-dimensional block universe, the spacetime of relativistic physics ${ }^{9}$ (in virtue of which it is sometimes also called the Scientific view of time), where past, present and future things equally exist, and the present time and non-present times are metaphysically the same. On this view, for the present time to be present does not designate anything of metaphysical significance, as 'present' is an indexical expression that refers to the time of utterance of such expression.

Consider dinosaurs, for example. B-theorists hold that dinosaurs exist very much as you and me; and the same goes for times: B-theorists think that the time at which dinosaurs are located exists very much as this time, the time at which we are located. In fact, B-theorists think of time as very similar to space: very much as all places, and things located at such places, equally exist, all times, and things located at such times, equally exist. To this, B-theorists add that as for some place to be the place that is here does not designate anything of metaphysical importance, for some time to be the time that is present does not designate anything of metaphysical importance: 'here' and 'present' are merely indexical expressions that refer, respectively, to the place and time at which they are uttered.

A further B-theoretic commitment on which I want to focus is how Btheorists usually interpret tenses and tense operators, as this will help to introduce the B-theoretical readings of Existential Change, Qualitative Change plus Persistence and Propositional Change. B-theorists think of tense operators as being fully reducible; to describe how reality ultimately looks like, B-theorists do not make use of any tense operator. This idea is captured by what Sider says in following quotation:

[B-theorists] do not admit tense operators into their fundamental ideology, since they can describe temporal reality

\footnotetext{
${ }^{8}$ Some supporters of the B-theory include Deng (2013), Dyke (2002), Leininger (2021), Mozersky (2015) and Sider (2001; 2011) and Williams (1951).

${ }^{9}$ As characterized by the pioneering research of Einstein (1952) and Minkowski (1952).
} 
without them-by quantifying over past and future entities and predicating features of them relative to times. (Sider 2011, 241)

Now we have all the ingredients we need to proceed with the discussion. Let's begin by exploring the connection between Existential Change and the B-theory.

\section{Existential Change and the B-theory}

Existential Change is the view that things change with respect to their existence, and B-theorists might happily grant that Existential Change is true on the B-theory. Consider the more formal version of Existential Change, namely 'Sometimes, something is not always something'. Now, there is a reading of Existential Change that is true on the B-theory, and to see that we must be clear about what it is for something to be such that it is sometimes something, or that it sometimes exists. As stated in the previous section, tense operators such as 'Sometimes' or, equivalently, 'It is sometime the case that' are fully reducible on the B-theory. ${ }^{10}$ In fact, according to B-theorists, tense operators are fully reducible to quantifiers over past, present and future times, as Sider makes clear in the passage quoted in the previous section: for something to be such that it sometimes exists is for it to be such that there is a time at which it exists. In other words, B-theorists reduce expressions of the form 'sometimes, $x$ exists' to expressions of the form ' $x$ exists at some time $t$ '. Accordingly, Existential Change reduces to the following:

EC-1: For some times $t$ and $t_{1}$, some $x$ is such that $x$ exists at $t$ but $x$ does not exist at $t_{1}$

And EC-1 is true on the B-theory. Consider dinosaurs, for example: it is true that dinosaurs exist at some times but not at others.

However, contemporary research on the topic suggests that expressions of the form ' $x$ exists at $t$ ' are inherently ambiguous (Correia and Rosenkranz 2019; Deasy 2019; Markosian 2014): on one reading, they are equivalent to expressions of the form ' $x$ is located at $t$ '; whereas on another reading, they are equivalent to expressions of the form 'at $t, x$ is something'. Thus, on the first reading, ' $x$ exists at $t$ ' is understood in locational terms, such

${ }^{10}$ Defenders of Existential Change like Prior (1968) or Crisp (2007) accept the partial (but not full) reducibility of tense operators to quantifiers over times, where times are intended as maximal, consistent, and sometimes-true propositions. However, since times are defined as "sometimes true" propositions, tense operators do not fully reduce to quantifiers over times. 
that to say that something exists at a time is to make a claim about where things are located in time; on the second reading, ' $x$ exists at $t$ ' is understood in perspectival terms, such that to say that something exists at a time $t$ is to make a claim about what there is relative to (i.e. from the perspective of) $t$.

If expressions of the form ' $x$ exists at $t$ ' are equivalent to expressions of the form ' $x$ is located at $t$ ', then Existential Change is true on the B-theory, since one can think of EC-1 as equivalent to the following:

EC-2: For some times $t$ and $t_{1}$, some $x$ is such that $x$ is located at $t$ but $x$ is not located at $t_{1}$

EC-2 is true on the B-theory.

However, one can read Existential Change as a thesis about what there is in time, rather than about where things are located in time. On this reading, Existential Change becomes a thesis about there being change in what there is over time. And on this reading, Existential Change is false on the Btheory. Or so I argue.

In order to develop this argument, I wish to consider the modal analogue of the B-theory, namely Modal Realism, on which actual things exist just as possible things do, and the actual world and non-actual worlds are metaphysically the same, notably defended by Lewis (1986). Modal Realists understand expressions of the form ' $x$ exists at world $w$ ' very much as B-theorists understand expressions of the form ' $x$ exists at time $t$ '. Accordingly, we can disambiguate between two readings of expressions of the form ' $x$ exists at world $w$ ', as either equivalent to ' $x$ is located at $w$ ' or 'at $w, x$ is something'.

Now, consider the following quotation from Lewis (1986):

The phrase 'at $\mathrm{W}$ ' which appears within the scope of the quantifier, [...] works mainly by restricting the domains of quantifiers in its scope, in much the same way that the restricting modifier 'in Australia' does. [...] [However] I do not suppose that they must restrict all quantifiers in their scope, without exception. [...] 'At some small worlds, there is a natural number too big to measure any class of individuals' can be true even if the large number that makes it true is no part of the small world. (Lewis 1986, 6) 
In the first half of the quotation, Lewis is referring to the first reading of ' $x$ exists at world $w$ ', where $w$, a world, is where some $x$ is located. In the second half of the quotation, Lewis speaks of the second reading of ' $x$ exists at world $w$ ', and says that sentences such as 'At $w$, there is a natural number too big to measure any class of individuals' can be true, even if such natural number is not located at $w$. In other words, irrespective of the location of such natural number, it is true of it that it is something, or it exists, given Modal Realism. So, Lewis is here suggesting that when attached to claims about what there is, irrespective of the location, in the modal space, the phrase 'at $w$ ' is irrelevant: that there is a natural number too big to measure any class of individuals is true even at worlds at which it is not located.

Let's apply the understanding of expressions of the form 'at $t, x$ is something' proposed by Lewis to the temporal case. To do so, consider the sentence 'at $t$, there is a dinosaur': 'There is a dinosaur' is true on the Btheory, even if there are no dinosaurs located at $t$. So, when attached to claims about what there is, irrespective of the location, in time, the phrase 'at $t$ ' seems to be irrelevant on the B-theory too: 'There is a dinosaur' is true on the B-theory, even at times at which dinosaurs are not located.

In light of that, one can argue that there is a reading of Existential Change that is false on the B-theory as there is a reading of Permanentism, the view that 'Everything always exists', namely the negation of Existential Change, which is true on the B-theory. To see that, let's reduce Permanentism to the view 'Everything exists at every time', ${ }^{11}$ and let's disambiguate between two versions of Permanentism in accordance with the disambiguation of the expression ' $x$ exists at $t$ ':

\section{P1: Everything is located at every time \\ $\mathrm{P} 2$ : At every time, everything is something}

P1 appears to be false: ${ }^{12}$ it is false that dinosaurs are located at every time, as they are not located at this time. However, 'Everything is something' is (trivially) true at every time: it is true at this time that some dinosaur exists, for example, even though there are no dinosaurs located at this time. So, there is a reading of Permanentism, namely P2, that is true on the B-theory.

\footnotetext{
${ }^{11}$ Given the reducibility of tense operators proposed by B-theorists, for something to be always something is for it to exist at every time.

${ }^{12}$ Unless one accepts some less-standard view on which, for example, there are just eternally existent atoms. On this view, P1 turns out to be true.
} 
However, when ' $x$ exists at $t$ ' is read at 'at $t, x$ is something', namely when expressions of the form ' $x$ exists at $t$ ' are read as making claims about what there is, irrespective of the location, in time, P2 is equivalent to Permanentism. In very much the same way, one can read Existential Change as making a claim about what there is, irrespective of the location, in time:

EC-3: for some times $t$ and $t_{1}$, at $t, x$ is something and at $t_{1} x$ is nothing

However, the B-theory is inconsistent with this reading of Existential Change, since on the B-theory there is no change in what there is, irrespective of the location, in time.

As we have seen, there is a sense in which Existential Change is true on the B-theory, and so in this sense there is change on the B-theory; however, there is also a reading of Existential Change that is inconsistent with the B-theory, such that in this other sense, there is no change on the B-theory. We can make a very similar claim with respect to Qualitative Change plus Persistence, as I argue in the following section.

\section{Qualitative Change plus Persistence and the B-theory}

As we needed to be clear about what is for something to sometimes exist on the B-theory, in order to explore its connection with Existential Change, we now have to be clear about what is for something to sometimes bear some property on the B-theory, in order to explore the connection between the B-theory and Qualitative Change plus Persistence (from now on, simply QCP). ${ }^{13}$

Think again of the above quotation from Sider $(2011,241)$. Sider remarks that B-theorists can describe things over time by "predicating features of them relative to times (italic mine)", such that for something to sometimes bear some property is for it to bear some property at some time. Therefore, $\mathrm{B}$-theorists think of expressions of the form 'sometimes, $x$ is F' as reducing to ' $x$ bears $\mathrm{F}$ at some time $t$ '. However, different B-theorists understand expressions of the form ' $x$ bears $\mathrm{F}$ at some time $t$ ' in different ways. In this section, I explore different B-theoretical interpretations of such expression, and I explore their connection with QCP.

\footnotetext{
${ }^{13}$ For a discussion of how the B-theory connects with what I call Qualitative Change plus Persistence see Cameron (2015, 152-159) and Wasserman (2006).
} 
To begin with, consider what Lewis says in the following quotation:

Let us say that something persists iff, somehow or other, it exists at various times; this is the neutral word. Something perdures iff it persists by having different temporal parts, or stages, at different times, though no one part of it is wholly present at more than one time; whereas it endures iff it persists by being wholly present at more than one time. (Lewis 1986, 202)

Accordingly, Perdurance is the view on which things persist by perduring and Endurance is the view that things persist by enduring. More recently, philosophers have introduced a further notion of persistence called Exdurance (Hawley 2001; Sider 1996), on which things persist by exduring, namely by having different temporal counterparts at different times. Depending on whether one endorses Perdurance, Endurance or Exdurance (plus the B-theory) one delivers a different interpretation of ' $x$ bears $\mathrm{F}$ at $t$ '. My plan in what follows is to discuss each option in order.

\subsection{B-theoretic Perdurance}

Perdurance as defended, for example, by Heller (1984), Lewis (1986) and Quine (1950) is the view that things persist by having different temporal parts at different times. Think of Lisa again. Lisa persists by having different temporal parts at different times. Then, on Perdurance, for Lisa to change from being standing to being seated, is for Lisa to have a temporal part that is standing and a later temporal part that is seated.

For the sake of a better understanding of Perdurance, we must get a better grip on what temporal parts are. Temporal parts are usefully characterized by analogy with spatial parts: as things have spatial parts, such as Lisa has a spatial part, such as her arm, and another spatial part, such as her leg, Lisa also has temporal parts, such as one that is standing and another that is seated.

Both spatial and temporal parts can be understood as spatially and temporally extended: as Lisa's arm is extended through space, Lisa's temporal part that is standing can be taken to be temporally extended too. However, as Lewis (and many others) defines the notion of temporal parts, temporal parts exist at times, and since times are instantaneous objects, temporal parts are naturally understood as instantaneous too: thus, $x$ is an instantaneous temporal part of $y$ if and only if (Sider 2001, 59) $x$ is part of $y, x$ overlaps, or shares, any part of $y$, and $x$ exists only at a single time. In 
what follows, for the sake of simplicity, when I speak of 'temporal parts' I mean 'instantaneous temporal parts'.

Thus, perdurantists naturally read expressions of the form ' $x$ bears $\mathrm{F}$ at $t$ ' as equivalent to 'one of $x$ 's temporal parts is $\mathrm{F}$ and is located at $t$ '. Accordingly, there is a reading of QCP that is true on the B-theory, namely:

QCP-1: for some times $t$ and $t_{1}$, there is some $x, y$ and $z$ such that $y$, one of $x$ 's temporal parts, is $\mathrm{F}$ and is located at $t$, and $\mathrm{z}$, another of $x$ 's temporal parts, is not-F and is located at $t_{1}$

So, perdurantists accept the truth of QCP by treating possession of properties as possession of properties relative to times; and then, by analysing possession of properties relative to times as possession of properties by temporal parts. In this sense, there is change on B-theory, as there is change given Perdurance.

However, there is also a reading of QCP that is ultimately inconsistent with Perdurance. Let me expand on that. On this alternative reading, it is Lisa the thing that is seated simpliciter and it is Lisa who changes with respect to that property. On the contrary, defenders of B-theoretic Perdurance think that it is not Lisa, but one of her temporal parts - call it T-Lisa - which is seated simpliciter. However, as an instantaneous object, T-Lisa does not persist, and therefore does not change with respect to her being seated, as there is no other time at which it is located and bears the property of being standing. So, T-Lisa does not change with respect to the property of being seated: T-Lisa is always seated.

The result is that B-theoretic Perdurantists reduce QCP to the eternal possession (simpliciter) of properties by temporal parts. Moreover, on the assumption that there is a sense in which B-theorists accept Permanentism-the view that everything always exists-B-theorists accept that in some sense it is true that temporal parts always exist. So, B-theoretic Perdurantists reduce QCP to the eternal possession of properties by eternally existent temporal parts. But one can read QCP as being about Lisa's changing with respect to her properties while persisting through time, while the B-theoretic Perdurantist's explanation of such a phenomenon bottoms out in permanent facts about the eternal properties of (eternal) temporal parts. B-theoretic Perdurance is thus inconsistent with this reading of QCP.

In the next section I show how a similar argument applies to B-theoretic Exdurance too. 


\subsection{B-theoretic Exdurance}

Distinct from Perdurance, Exdurance as defended by, for instance, Hawley (2001) and Sider (1996), among others, is the view that ordinary things are not temporally extended things, but instantaneous temporal parts, or stages, and for something to persist is for it to have different temporal counterparts at different times. Think of Lisa: Lisa persists by having different temporal counterparts at different times. Then, on Exdurance, for Lisa to change from being standing to being seated, is for Lisa, an instantaneous stage, to be seated, and to have a temporal counterpart that is standing.

One of the main novelties of Exdurance is the introduction of the notion of temporal counterparts: to get a better sense about what a temporal counterpart is, an analogy with the modal case is instructive. David Lewis' notion of modal counterpart (Lewis 1968) is probably the best place for that: the point here is to get a sense of how, for example, Lisa modally persists. For Lisa to modally persist is for Lisa to have various modal counterparts at various worlds, where for something to be a modal counterpart of Lisa is to resemble Lisa in all her relevant features (Lewis 1968, 114; Sider 2001, 111-2). For example, 'Lisa is seated but might be standing' is true because Lisa modally persists by having a modal counterpart at some world, which resembles Lisa in all her relevant features, and it is standing. The same applies to the temporal case. For Lisa to persist is for Lisa to have different temporal counterparts at various times, which resemble Lisa in all her relevant features. Then, 'Lisa is seated but was standing' is true because the Lisa that is seated has a temporal counterpart at some time, which resembles Lisa in all her relevant features, and it is standing.

Thus, Exdurantists naturally read expressions of the form ' $x$ is $\mathrm{F}$ at $t$ ' as ' $x$ is $\mathrm{F}$ and is located at $t$ ', by treating the variable ' $x$ ' as taking in only instantaneous stages. In other words, according to Exdurantists, the name 'Lisa' does not refer to an object that exists at different times, but to an instantaneous stage. Accordingly, there is a reading of QCP that is true on the B-theory, namely:

QCP-2: for some times $t$ and $t_{1}$, there is some $x$ such that $x$ is $\mathrm{F}$ and is located at $t$, and there is some $y$, one of $x$ 's temporal counterparts, such that $y$ is not-F and is located at $t_{1}$

So, exdurantists accept QCP by treating possession of properties as possession of properties relative to times; and then, by analysing possession of properties relative to times as possession of properties by 
instantaneous stages. In this sense, there is change on the B-theory, as there is change given Exdurance.

Still, there is an alternative reading of QCP that is ultimately inconsistent with Exdurance. On this reading of QCP, it is Lisa who is seated, and it is that thing that persists through time: distinct from defenders of Perdurance, defenders of Exdurance accept that. However, on this reading of QCP, 'Lisa' refers to a temporally extended object and not to an instantaneous thing, as it does according to Exdurance. In light of that, there is a sense in which things do not persist given Exdurance, and that's the sense in which things persist given this reading of QCP: Lisa exists, but did exist and will exist too. As an instantaneous thing, however, Lisa does not persist in this sense on Exdurance: instantaneous things are, by definition, things that do not exist at multiple times, and in this sense, it is false that Lisa did exist and will exist too given Exdurance.

So, in that sense, Lisa does not persist on Exdurance; but if Lisa does not persist in this sense, Lisa does not change too, as there is no other time at which it exists and is, for example, standing. If she does not change and persist in this sense, namely the sense in which things change and persist given this reading of QCP do, Exdurance is inconsistent with this reading of QCP. Thus, there is no change on the B-theory, as there is no change on Exdurance.

There are further elements that make one worry about the consistency of QCP, on this reading, and Exdurance. First, while given this reading of QCP, the Lisa that exists and is seated is one and the same with the Lisa that did exist and was standing, given Exdurance, the Lisa that exists and is seated is not one and the same with her earlier temporal counterpart that is standing. As a matter of fact, given Exdurance, the two are not identical, but resemble each other with respect to their relevant features. Such resemblance-relation, however, is deliberately context sensitive, as it is the notion of "relevant features". As a matter of fact, we may deliberately refer to one set of features $\mathrm{S}$ in one context according to which the Lisa that is seated and the Lisa that is standing resemble each other, and to another set of features $\mathrm{S}^{*}$ in another context according to which the two do not resemble each other.

As a consequence, there is no fixed set of relevant features according to which temporal counterparts resemble each other: such set varies from situation to situation and the choice of such set is entirely arbitrary. However, on Exdurance things persist by being related via a relation of resemblance in relevant features; so, Persistence becomes a deliberately context sensitive phenomenon as well. On the contrary, given the reading 
of QCP under consideration, Persistence is not deliberately context sensitive: it is one and the same thing, namely Lisa, that changes and persists over time.

Moreover, given Exdurance, we have a series of instantaneous stages that persist by resembling each other with respect to some relevant features. In other words, we have a series of instantaneous stages lined up in time, related to one another by a relation of resemblance in all the relevant features. In such a series, we have the Lisa that is seated and the Lisa that is standing. But who is the persisting Lisa? This Lisa, namely the Lisa that is seated, or that Lisa, the Lisa that is standing? The choice is entirely arbitrary. ${ }^{14}$ On the contrary, given the reading of QCP under consideration, there is no choice to be made: there's only one Lisa, and that's the persisting thing, and that's the Lisa that is seated.

Exdurance is thus inconsistent with this reading of QCP, and in this sense there is no change on Exdurance, and then on the B-theory. Let's now move to the final view I wish to discuss, namely B-theoretic Endurance.

\subsection{B-theoretic Endurance}

Endurance, as defined by Lewis, is the view that things persist by being wholly present at different times. Defining Endurance in these terms raises several difficulties. ${ }^{15}$ It is not my aim here to try to fix some of such difficulties. What I plan to do, instead, is to look at a couple of ways in which self-described endurantists characterize the view and expand on their connection with QCP.

\subsubsection{B-theoretic Relationalism}

Let's begin with the view I call Relationalism as defended by Mellor (1998) and Mozersky (2015), among others, according to which expressions of the form ' $x$ is $\mathrm{F}$ at $t$ ' are interpreted as ' $x$ is F-at- $t$ ', namely the view on which things have different time-indexed properties. Timeindexed properties are properties such as being-a-kid-at- $t$ or being-red-at$t_{1}$ and so on. Think of Lisa: for Lisa to change from being standing to being seated, given Relationalism, is for Lisa to be standing-at- $t_{1}$ and to be seated-at- $t$.

\footnotetext{
${ }^{14}$ Note that the question is not "who is the Lisa that is seated?", as the Lisa that is seated is plausibly taken to be the Lisa that exists at the time of utterance of the sentence 'Lisa is seated'.

${ }^{15}$ See Sider (2001, 63-68) for a discussion of such problems.
} 
Granted the relationalist's reading of expressions of the form ' $x$ is $\mathrm{F}$ at $t$ ', there is a reading of QCP that is true on the B-theory, namely:

QCP-3: for two times $t$ and $t_{1}$, there is some $x$ such that $x$ is F-at- $t$ and not-F-at- $t_{1}$

So, Relationalists accept QCP by treating possession of properties as possession of properties relative to times; and then, by treating properties as time-indexed properties, where the index corresponds to time relative to which the relevant property is said to be possessed in the first place. ${ }^{16}$ In this sense, there is change on the B-theory, as there is change on Relationalism.

While there is a reading of QCP that is true given Relationalism, there is a further reading of QCP that is inconsistent with Relationalism: on this reading, Lisa changes with respect to her being seated, and being seated is a temporary property. I claim that what are temporary properties given this reading of QCP become eternal properties given Relationalism. To see that, consider the property of being seated: given QCP, being seated is a temporary property, where a temporary property is a property that is sometimes but not always possessed. As a matter of fact, Lisa is seated, but not always seated. In other words, Lisa does not bear any indexed property such as the property of being-seated-at- $t$, as she is simply seated, and not always so.

On the contrary, B-theoretic Relationalists think that for Lisa to be such that she was standing and is seated reduces to her bearing the properties of being-standing-at- $t_{1}$ and being-seated-at- $t$, where $t_{1}$ is earlier than $t$. The problem is then that Lisa never changes with respect to being-seated-at- $t$ and being-standing-at- $t_{1}$. Consider being-seated-at- $t$ : being-seated-at- $t$ is an eternal property, where for a property to be eternal given the B-theory is for it to be such that if something bears it, it always bears it. ${ }^{17}$ As a matter of fact, it is true at every time that Lisa bears the property of being-seatedat- $t$. If so, however, Lisa never changes with respect to this property: Lisa is always seated-at- $t$.

Given the reading of QCP under consideration, however, Lisa changes with respect to the property of being seated, which is a temporary, rather than eternal, property, that is a property that Lisa has, but not always. Even

\footnotetext{
16 The view is notably criticized in Lewis $(1986,204)$, with the so called temporary intrinsics objection.

${ }^{17}$ It is important to notice that unlike the B-theory, on the view on which there is change in what exists, irrespective of the location, in time, a property that something always bears, namely an eternal property, would be a property that something bears whenever it exists.
} 
if B-theoretic Relationalists attempt to explain this reading of QCP, they do so by reducing temporary properties onto eternal ones, such as timeindexed properties. Since, on this reading QCP, properties such as being seated are temporary, rather than eternal, B-theoretic Relationalism is ultimately inconsistent with it.

Before concluding this section, I wish to consider a slightly different version of Relationalism as defended, for example, by van Inwagen (1990): ${ }^{18}$ on this view, expressions of the form ' $x$ is $\mathrm{F}$ at $t$ ' are interpreted as ' $x$ is-F-at $t$ ', namely the view on which things bear different relations with different times. Think of Lisa again: for Lisa to change from being standing to being seated, given this version of Relationalism, is for Lisa to be-standing-at $t_{1}$ and to be-seated-at $t$.

I am persuaded to think that this version of Relationalism is inconsistent with the reading of QCP under consideration too. As a matter of fact, very much as time-indexed properties, relations to times always hold: Lisa always bears the relation of being-standing-at with $t_{1}$ and the relation of being-seated-at with $t$. On this reading of QCP, being seated, for example, is a temporary property, that becomes a permanent relation that Lisa bears with some time given this version of Relationalism. Therefore, also this version of Relationalism is inconsistent with this reading of QCP.

\subsubsection{B-theoretic Adverbialism}

Adverbialism, the view defended by Haslanger (1989), Johnston and Forbes (1987) and Miller and Braddon-Mitchell (2007), among others, is the view according to which expressions of the form ' $x$ is $\mathrm{F}$ at $t$ ' reduce to ' $x$ is-at- $t \mathrm{~F}$ ', where the instantiation-relation between properties and their bearers is time-indexed. Then, for Lisa to change from being standing to being seated is for Lisa to be-at- $t_{1}$ standing and to be-at- $t$ seated.

Granted the adverbialist's understanding of expressions of the form ' $x$ is $\mathrm{F}$ at $t^{\prime}$, there is a reading of QCP that is true one the B-theory:

QCP-4: for some times $t$ and $t_{1}$, there is some $x$ such that $x$ is-at- $t \mathrm{~F}$ and $x$ is-not-at- $t_{1} \mathrm{~F}$

So, Adverbialists accept QCP by treating possession of properties as possession of properties relative to times; and then, by treating the instantiation-relation as time-indexed, where the index corresponds to time

${ }^{18}$ Thanks to an anonymous reviewer for this journal for pressing me to consider this version of Relationalism too. 
relative to which the relevant property is said to be possessed in the first place. In this sense, there is change on the B-theory, as there is change on Adverbialism. ${ }^{19}$

I think that there is an argument like the one I raised against B-theoretic Relationalism to show that there is a reading of QCP that is inconsistent with B-theoretic Adverbialism: on this reading of QCP, Lisa changes with respect to her being seated, as she is temporarily seated. ${ }^{20}$ What I believe to be problematic is that there is a reading of QCP on which temporary ways of bearing properties are transformed into eternal ways given Btheoretic Adverbialism. If we say that for something to bear a property temporarily is for it to be such that it bears some property but not always, then on this reading of QCP, Lisa, for instance, temporarily bears the property of being seated, as she is seated but not always so. In other words, Lisa does not bear-at- $t$ some property, but she simply bears the property of being seated. However, very much as time-indexed properties are always had, the time-indexed instantiation-relation always holds, since if something bears-at- $t$ some property $F$, it always bears-at- $t F$. As a matter of fact, bearing-at- $t$ is an eternal way of bearing properties: things do not change with respect to their bearing certain properties if they bear-at-times properties. Given our example, for Lisa to be-at- $t$ seated is for Lisa to always be-at- $t$ seated, as it is the case at every time that Lisa is-at- $t$ seated: Lisa does not change with respect to her being-at- $t$ seated.

On the contrary, on the reading of QCP under consideration, Lisa changes with respect to her being seated, as Lisa temporarily bears the property of being seated. Even if B-theoretic Adverbialists attempt to explain this reading of QCP, they do so by reducing the temporary instantiation of properties to an eternal one, such as the time-indexed instantiation of properties. Since on this reading of QCP, the instantiation of properties is temporary, rather than eternal, B-theoretic Adverbialism is ultimately inconsistent with it.

This concludes the discussion of how the B-theory connects with QCP. In the following, and last, section, I plan to say more about Propositional Change and the B-theory of time.

${ }^{19}$ For a famous objection against Adverbialism see Lewis (2002), according to whom Adverbialism lands us in a version of Bradley's regress.

${ }^{20}$ For some objections to Adverbialism see Lewis (2002). 


\section{Propositional Change and the B-theory}

In Section 1 of this paper, I argued that one can derive Propositional Change from either Existential Change or Qualitative Change plus Persistence: since Lisa exists, but not always, the proposition that Lisa exists is true, but not always; analogously, since Lisa is seated, but not always, the proposition that Lisa is seated is true, but not always.

From this, one can infer that since there is a reading of Existential Change and Qualitative Change plus Persistence that is inconsistent with the Btheory, there is a reading of Propositional Change that is inconsistent with the B-theory. Let's expand on that.

To begin with, let's consider B-theoretical views on which expressions of the form 'sometimes, $p$ is true' are interpreted as ' $p$ is true at $t$ ', namely on which propositions have truth-value relative to times. Here are two versions of the B-theoretic proposal: on one conception, analogous to the modal case where propositions are properties of worlds, propositions are considered as properties of instants (Lewis 1979); on another conception, propositions are functions from instants to truth values (Sider 2001, 20-1). On both views, Propositional Change is true because the following is true:

PC-1: for some times $t$ and $t_{1}$, there is some $p$ such that $p$ is true at $t$, but $p$ is not true at $t_{1}$

More precisely, on the view that propositions are properties of instants, to say that the proposition that Lisa exists is true relative to a certain time $t$ is just to say that $t$ possesses the property of being a time at which Lisa exists. Hence, on this view, to say that a certain proposition changes in truth value over time is just to say that the property $\mathrm{F}$ of times identified with that proposition is possessed by some but not all times.

On the view on which propositions are functions from times to truth values, the truth of that Lisa exists depends on the instant of time we plug into the function. Hence, to say that propositions change in truth value is to say that the function $f$ identified with a proposition delivers truth for some but not all times as inputs. In both views, Propositional Change turns out to be true, and therefore there is change in this sense on the B-theory.

In doing so, both views preserve the truth of Propositional Change by interpreting what is for something to be sometimes true in terms of truthrelative to times. Doing that, however, make them inconsistent with an alternative reading of Propositional Change: on this reading of Propositional Change, propositions are not true relative to times, very 
much as one can read Existential Change as the view on which things do not exist relative to times, and one can read Qualitative Change plus Persistence as the view on which things do not have properties relative to times. On this reading, propositions have truth values simpliciter.

So, on this reading of Propositional Change, some proposition, such as that Lisa exists, is true simpliciter, but not always. On this reading of Propositional Change, propositions do not change with respect to truth value if they always have the truth value they have. In fact, on this reading of Propositional Change, propositions that are true relative to times, are always true if true: if it is true at $t$ that Lisa is seated, it is always true at $t$ that Lisa is seated, as it is true at every time that it is true at $t$ that Lisa is seated. Thus, on this reading of Propositional Change, propositions that are true relative to times always have the truth value they have. Thus, treating truth as relative to times lead to a reduction of Propositional Change, such as PC1, which is ultimately inconsistent with the reading of Propositional Change under consideration.

\section{Conclusion}

The result of this paper is that, granted different understandings of what it is for things to change, we end up having different responses to the question as to whether there is change on the B-theory. By considering three instances of change, such as Existential Change, Qualitative Change plus Persistence and Propositional Change, I argued that we can read those theses such that they are all true on the B-theory. In this sense, there is change on the B-theory. However, I claimed there are alternative readings of each of them that are false on the B-theory: so, in this other sense, there is no change on the B-theory.

\section{Acknowledgments}

I would like to thank Daniel Esmonde Deasy and Antoine Athanassiadis for many helpful conversations and comments on the material of this paper.

\section{REFERENCES}

Bacon, Andrew. 2013. 'Quantificational Logic and Empty Names'. Philosophers' Imprint 13 (24): 1-21. http://hdl.handle.net/2027/spo.3521354.0013.024. 
Cameron, Ross. 2015. The Moving Spotlight. Oxford: Oxford University Press.

Cappelen, Herman, and John Hawthorne. 2009. Relativism and Monadic Truth. Oxford: Oxford University Press.

Crisp, Thomas M. 2007. 'Presentism and the Grounding Objection'. Noûs 41 (1): 90-109. https://doi.org/10.1111/j.1468-0068.2007.00639.x.

Correia, Fabrice, and Sven Rosenkranz. 2018. Nothing to Come. Berlin: Springer.

Correia, Fabrice, and Sven Rosenkranz. 2020. 'Temporal Existence and Temporal Location'. Philosophical Studies 177 (7): 1999-2011. https://doi.org/10.1007/s11098-019-01295-z

Deasy, Daniel. 2019. 'Characterising Theories of Time and Modality'. Analytic Philosophy 60 (3): 283-305.

https://doi.org/10.1111/phib.12147.

Deng, Natalja. 2013. 'Fine's McTaggart, Temporal Passage, and the A Versus B-debate'. Ratio 26 (1): 19-34. https://doi.org/10.1111/j.1467-9329.2012.00526.x.

Dyke, Heather. 2002. 'McTaggart and the truth about time'. In Time, reality, and axperience, edited by Craig Callender, 137-152. Cambridge: Cambridge University Press.

Einstein, Albert. 1952. 'On the Electrodynamics of Moving Bodies'. In The Principle of Relativity, edited by Arnold Sommerfeld, 3565. New York: Dover Publishing.

Haslanger, Sally. 1989. 'Endurance and Temporary Intrinsics'. Analysis 49 (3): 119-125. https://doi.org/10.2307/3328113.

Hawley, Katherine. 2001. How Things Persist. Oxford: Oxford University Press.

Heller, Mark. 1984. 'Temporal Parts of Four Dimensional Objects'. Philosophical Studies 46 (3): 323-334. https://doi.org/10.1007/bf00372910.

Hinchliff, Mark. 1996. 'The Puzzle of Change'. Philosophical Perspectives 10: 119-136. https://doi.org/10.2307/2216239.

Johnston, Mark and Graeme Forbes. 1987. 'Is There a Problem About Persistence?'. Aristotelian Society Supplementary Volume 61 (1): 107-156.

https://doi.org/10.1093/aristoteliansupp/61.1.107.

Leininger, Lisa. 2021. 'Temporal B-coming: Passage Without Presentness'. Australasian Journal of Philosophy 99 (1): 130147.

https://doi.org/10.1080/00048402.2020.1744673. 
Lewis, David K. 1968. 'Counterpart Theory and Quantified Modal Logic'. Journal of Philosophy 65 (5): 113-126.

https://doi.org/10.2307/2024555.

Lewis, David K. 1979. 'Attitudes De Dicto and De Se'. The Philosophical Review 88 (4): 513-543. https://doi.org/10.2307/2184843.

Lewis, David K. 1986. On the Plurality of Worlds. Oxford: Blackwell.

Lewis, David K. 2002. 'Tensing the Copula'. Mind 111 (441): 1-13. https://doi.org/10.1093/mind/111.441.1.

Lowe, Jonathan E. 2003. 'Substantial Change and Spatiotemporal Coincidence'. Ratio 16 (2): 140-160.

https://doi.org/10.1111/1467-9329.00212.

Lowe, Jonathan E. 2006. 'How Real is Substantial Change?'. Monist 89 (3) $275-293$.

https://doi.org/10.5840/monist200689312.

Lowe, Jonathan E. 2009. 'Serious Endurantism and the Strong Unity of Human Persons'. In Unity and Time in Metaphysics, edited by Ludger Honnefelder, Benedikt Schick and Edmund Runggaldier, 67-82. Berlin: Walter de Gruyter.

Markosian, Ned. 2014. Time. The Stanford Encyclopedia of Philosophy.

Edited by Edward N. Zalta. Accessed November 17, 2020.

https://plato.stanford.edu/entries/time/\#TheBThe

McTaggart, John. M. E. 1927. The Nature of Existence: Volume II. Cambridge: Cambridge University Press.

Mellor, Hugh. 1998. Real Time II. London: Routledge.

Miller, Kristie, and David Braddon-Mitchell. 2007. 'There Is No Simpliciter Simpliciter'. Philosophical Studies 136 (2): 249-278. https://doi.org/10.1007/s11098-007-9074-3.

Minkowski, Hermann. 1952. 'Space and time', In The Principle of Relativity, edited by Arnold Sommerfeld, 73-91. New York: Dover Publishing.

Mozersky, Joshua. 2015. Time, Language and Ontology. Oxford: Oxford University Press.

Prior, Arthur. 1968. Papers on Time and Tense. Oxford: Oxford University Press.

Quine, Willard V. 1950. 'Identity, Ostension, and Hypostasis'. The Journal of Philosophy 47 (22): 621-632.

https://doi.org/10.2307/2021795.

Sider, Ted. 1996. 'All the World's a Stage'. Australasian Journal of Philosophy 74 (3): 433-453.

https://doi.org/10.1080/00048409612347421.

Sider, Ted. 2001. Four-Dimensionalism. Oxford: Oxford University Press. Sider, Ted. 2011. Writing the Book of the World. Oxford: Oxford University Press. 
van Inwagen, Peter. 1990. 'Four-Dimensional Objects'. Noûs 24 (2): 24555.

https://doi.org/10.2307/2215526.

van Inwagen, Peter. 2009. 'Being, Existence, and Ontological Commitment'. In Metametaphysics, edited by David Chalmers, David Manley and Ryan Wasserman, 472-506. Oxford: Oxford University Press.

Wasserman, Ryan. 2006. 'The Problem of Change'. Philosophy Compass 1(1): 48-57.

https://doi.org/10.1111/j.1747-9991.2006.00012.x.

Williams, Donald C. 1951. 'The Myth of Passage'. The Journal of Philosophy 48 (15): 457-472. https://doi.org/10.2307/2021694.

Williamson, Timothy. 2002. 'Necessary Existents'. Royal Institute of Philosophy Supplement 51: 233-251. https://doi.org/10.1017/S1358246100008158.

Williamson, Timothy. 2013. Modal Logic as Metaphysics. Oxford: Oxford University Press.

Zimmerman, Dean W. (2008). 'The Privileged Present: Defending an "Atheory" of Time'. In Contemporary Debates in Metaphysics, edited by Ted Sider, John Hawthorne and Dean. W. Zimmerman, 211-225. Oxford: Blackwell. 
